\title{
TUYẾN GIÁP VÀ VÔ SINH NAM
}

Nguyê̂n Thị Thanh Huơng ${ }^{1}$, Vũ Bích $\mathrm{Nga}^{2}$

1. Bệnh viện Đại học Y Hà Nội;

2. Trường Đại học Y Hà Nộ

DOI: $10.47122 /$ vjde.2020.43.14

\section{ABSTRACT \\ Thyroid and male infertility}

The thyroid is the largest endocrine gland in the body. The thyroid hormones play an important role in many metabolic processes. Thyroid diseaseis the most common endocrine disease affecting women of reproductive age. Change sinthyroidfunction adversely affect female reproductive healthbefore, during and after conception. In addition, thyroid disease has long been considered a risk factor for miscarriage and may adversely affect perinatal outcome and mortality. Therefore, the author recently mentioned screening for thyroid disease in women with reproductive problems, recurrent miscarriages at the onset ofpregnancy. Incontrast to that, the effects of thyroid hormones on male reproductive function are largely unknown andrarely mentioned. The relationship between thyroid function and spermatogenesis in adult men and the way thyroid hormones affect testicular function remains controversial. There have been a few studies showing negative effects of hyperthyroidism and hypothyroidism on semen parameters. Hyperthyroidism has been found to be inversely related to sperm count and motility. Hypothyroidism has a negative effect on sperm motility, sperm morphology and semenvolume.

Key words: Thyroid, male infertility

\section{TÓM TẮT}

Tuyến giáp là tuyến nội tiết lớn nhất trong cơ thể. Hormone tuyến giáp tham gia vào các quá trình chuyển hóa quan trọng. Bệnh tuyến giáp là bệnh nội tiết phổ biến nhất ảnh hưởng đến phụ nữ trong độ tuổi sinh sản. Những thay đồi về chức năng tuyến giáp ảnh hưởng xấu đến sức khỏe sinh sản nữ trước, trong và sau khi thụ thai. Ngoài ra, bệnh tuyến giáp từ lâu đã được coi là một yếu tố nguy cơ gây sẩy thai và có thể có ảnh hưởng không tốt tới kết quả thai kỳ và tử vong chu sinh. Do đó, gần đây đã có tác giả đề cập đến việc sàng lọc bệnh lý tuyến giáp ở những phụ nữ có vấn đề về sinh sản, sảy thai tái phát ngay khi bắt đầu bước vào thai kỳ. Ngược lại với quan điểm cho rằng hormone tuyến giáp rất quan trọng đối với khả năng sinh sản của nữ, tác động của hormon tuyến giáp đến chức năng sinh sản của nam giới phần lớn chưa rõ và hiếm khi được đề cập. Mối quan hệ giữa chức năng tuyến giáp và sự sinh tinh trùng ở nam giới trưởng thành và cách hormon tuyến giáp tác động lên chức năng tinh hoàn vẫn còn gây nhiều tranh cãi. Đã có một vài nghiên cứu cho thấy tác động tiêu cực của cường giáp và suy giáp lên các thông số tinh dịch đồ. Người ta thấy cường giáp có mối liên hệ ngược với số lượng tinh trùng và sự vận động của tinh trùng. Suy giáp lại có ảnh hưởng tiêu cực đến khả năng vận động của tinh trùng, hình thái học tinh trùng và thể tích tinh dịch.

Tù khóa: tuyến giáp, vô sinh nam

Chịu trách nhiệm chính: Vũ Bích Nga

Ngày nhận bài: 05/8/2020

Ngày phản biện khoa học: 07/11/2020

Ngày duyệt bài: 13/12/2020

Email: vubichnga116@gmail.com

Điện thoại: 0913544622

\section{1. ĐĂT VẤn ĐỀ}

Tuyến giáp là tuyến nội tiết lớn nhất trong cơ thể. Tuyến giáp bài tiết các hormone tham gia vào các quá trình chuyển hóa quan trọng. Bệnh tuyến giáp là bệnh nội tiết phổ biến nhất ảnh hưởng đến phụ nữ trong độ tuổi sinh sản. Cường giáp gặp ở $2,3 \%$ phụ nữ có vấn đề về sinh sản[1], [11], suy giáp gặp ở khoảng 2 4\% phụ nữ trong độ tuổi sinh sản[1], [12], trong khi suy giáp cận lâm sàng gặp ở khoảng $11 \%$ những người bị rối loạn rụng trứng[13]. 
Những thay đổi về chức năng tuyến giáp ảnh hưởng xấu đến sức khỏe sinh sản nữ trước, trong và sau khi thụ thai [1], [2], [3]. Ngoài ra, bệnh tuyến giáp từ lâu đã được coi là một yếu tố nguy cơ cho sẩy thai và có thể có ảnh hưởng không tốt tới kết quả thai kỳ và tử vong chu sinh [3], [4]. Do đó, gần đây đã có tác giả đề cập đến việc sàng lọc bệnh lý tuyến giáp ở những phụ nữ có vấn đề về sinh sản, sảy thai tái phát ngay khi bắt đầu bước vào thai kỳ[1].

Ngược lại với quan điểm cho rằng hormone tuyến giáp rất quan trọng đối với khả năng sinh sản của nữ, tác động của hormon tuyến giáp đến chức năng sinh sản của nam giới phần lớn chưa rõ và hiếm khi được đề cập. Điều này có thể do tỷ lệ rối loạn chức năng tuyến giáp ở nam giới thấp hơn hoặc do tác động của hormon tuyến giáp lên chức năng sinh sản ít hơn so với các tác dụng toàn thân của chúng.

Trong vài thập kỷ gần đây, người ta đã bắt đầu nghiên cứu sâu về vai trò của hormone tuyến giáp đối với chức năng sinh sản nam giới. Chúng được xem như là các yếu tố thiết yếu điều hòa các chức năng sinh sản của nam giới và đóng vai trò quan trọng trong sự phát triển của tuyến sinh dục nam. Cả cường giáp và suy giáp đều ảnh hưởng đến chức năng tinh hoàn và ảnh hưởng đến sự điều hòa thần kinh nội tiết đối với chức năng sinh sản thông qua con đường chéo giữa trục dưới đồi-tuyến yên-tuyến giáp và trục hạ đồi-tuyến yên-tuyến sinh dục [14]. Những thay đổi hormone sinh dục nam do thay đổi hormone tuyến giáp có thể gây giảm nồng độ testosterone và suy giảm chất lượng tinh dịch.

Bài viết này nhằm mục đích cập nhật các kiến thức về vai trò của hormone tuyến giáp trong điều hòa các chức năng sinh sản của nam giới và cơ chế rối loạn tuyến giáp có thể làm thay đổi chức năng tinh hoàn và chất lượng tinh dịch.

\section{SINH LÝ TUYẾN GIÁP VÀ HỆ SINH SẢN NAM}

Hormone tuyến giáp được điều hòa bài tiết theo cơ chế feedback ngược, liên quan đến vùng dưới đồi, tuyến yên, tuyến giáp. TRH được bài tiết ở vùng dưới đồi và điều hòa bài tiết TSH. TSH là hormone của thùy trước tuyến yên, điều hòa tổng hợp và bài tiết hormone T3, T4 của tuyến giáp. TSH, TRH và các hormone tuyến giáp tạo nên trục dưới đồi - tuyến yên - tuyến giáp. Khi nồng độ hormone tuyến giáp trong máu tăng sẽ ức chế giải phóng $\mathrm{TRH}$ và $\mathrm{TSH}$, ngược lại khi hormone tuyến giáp giảm sẽ kích thích bài tiết $\mathrm{TRH}$ và TSH. Ở tuyến giáp, T4 được tổng hợp nhiều hơn T3, tuy nhiên T3 có hoạt tính sinh học mạnh hơn, vì các thụ thể của hormone tuyến giáp (TRs) có ái lực với T3 lớn hơn nhiều so với T4. Do vậy, khoảng $80 \%$ T4 do tuyến giáp tổng hợp được chuyển đổi thành $\mathrm{T} 3$.

Trong máu T3, T4 tồn tại chủ yếu dưới dạng gắn với protein huyết tương $(>99 \%)$, chỉ $0.04 \%$ T4 và $0.4 \%$ T3 là ở dạng tự do dạng có hoạt tính sinh học. Dạng tự do T3, T4 được vận chuyển vào trong tế bào đích nhờ co chế khuếch tán hoặc nhờ các protein mang đặc hiệu trên màng tế bào: MCT8, MCT10 và Oatpla. Trong các tế bào đích, T4 được chuyển thành $\mathrm{T} 3$ nhờ men deiodinase type 1 (D1) và type 2 (D2). Deiodinase type 3 (D3) chịu trách nhiệm bất hoạt hormon tuyến giáp bằng cách chuyển $\mathrm{T} 4$ và $\mathrm{T} 3$ thành $\mathrm{rT} 3$ và $\mathrm{T} 2$ tương ứng. $\mathrm{T} 3$ đi vào nhân tế bào và hoạt hóa receptor nhân trên DNA, kích thích hoặc kìm hãm sự biểu hiện của các gen phiên mã phụ thuộc vào đồng phân hóa receptor axit retinoic $X(R X R)$ và / hoặc bổ sung thêm các chất đồng hoạt hóa, chẳng hạn như chất đồng hoạt hóa thụ thể steroid (SRC). Ngoài các receptor nhân, các hormon tuyến giáp cũng có thể hoạt động bằng cách liên kết với $\alpha \mathrm{v} \beta 3$ Integrarin, có trong màng tế bào và kích hoạt dòng truyền tín hiệu qua MAPK và ERK1/2 để điều chỉnh quá trình phiên mã và phosphoryl hóa của các thụ thể nhân của nó.Sau khi hoạt hóa receptor, hormon tuyến giáp thực hiện chức năng điều hòa quá trình chuyển hóa carbohydrate, protein và lipid trong tất cả các tế bào, cũng như điều chỉnh sự biệt hóa và tăng sinh tế bào. Do đó, sự thay đổi nồng độ hormon tuyến giáp trong huyết 
tương có thể ảnh hưởng đến tất cả các cơ quan bao gồm cả tác dụng trên hệ thống sinh sản [15].

Người ta đã xác định được cả hai thụ thể hormone tuyến giáp TR $\alpha$ [3] và $\operatorname{TR} \beta$ [8-10] trong tinh hoàn người. Hai gen $(\mathrm{TR} \alpha$ và $T R \beta)$ mã hóa năm đồng phân thu được bằng cách ghép xen kẽ $(T R \alpha 1, T R \alpha 2, T R \alpha 3, T R \beta 1$ và
TR $\beta 2$ ). TR $\alpha 2$ và $T R \alpha 3$ không có vùng gắn với hormone và cạnh tranh với $\mathrm{T} 3$ về sự gắn kết của yếu tố đáp ứng hormone tuyến giáp (TRE), ức chế quá trình sao chép. Đặc biệt, TR $\alpha 1$ là dạng đồng phân chính trong tế bào mầm và trong tế bào Sertoli. Sự phát triển của tế bào mầm và tế bào Sertoli cũng được điều hòa bởi TR $\beta 1$ và TR $\beta 2[15]$, [16].

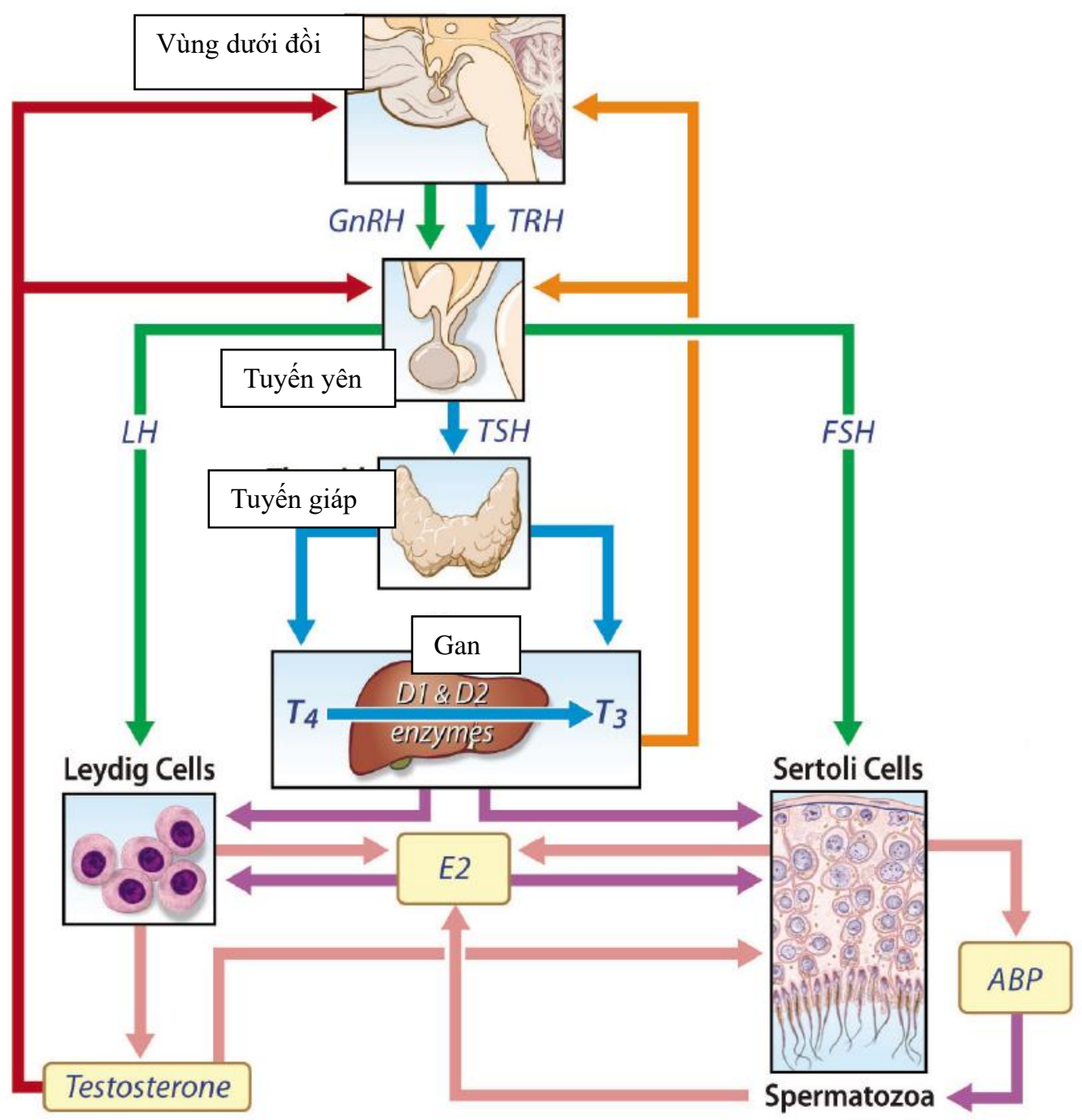

Hình 1. Tóm tắt vai trò của tuyến giáp trên sự phát triển và sinh tinh của tinh trùng và khả năng tương tác giữa trục dưới đồi - tuyến yên - tuyến sinh dục (HPG) và trục dưới đồi - tuyến yên tuyến giáp (HPT): trục HPG biểu hiện bởi mũi tên xanh lá cây (kích thích) và mũi tên đỏ (ức chế). Trục HPT biểu hiện bởi mũi tên xanh da trời (kích thích) và mũi tên cam (ức chế). Màu tím tượng trưng cho cơ chế hoặc vai trò chưa rõ [16]. 


\section{Ảnh hương trên các tế bào không phải tế bào mầm}

T3 tác động trên các tế bào không phải tế bào mầm bằng cách điều chỉnh sự tăng sinh và biệt hóa của chúng(Hình 1). Hormone tuyến giáp có tác động kép lên tế bào Sertoli. Nó ức chế sự tăng sinh tế bào Sertoli do kích thích tổng hợp hai chất ức chế kinase phụ thuộc cyclin (p27kip1 và $\mathrm{p} 21 \mathrm{cip} 1)$, và do đó ngăn chặn chu trình tế bào ở G1 [17]. Hormone tuyến giáp cũng thúc đẩy quá trình biệt hóa tế bào Sertoli [6], và ức chế sự tổng hợp các điểm nối giữa các tế bào Sertoli và tinh nguyên bào bằng cách giảm tổng hợp phân tử kết dính tế bào thần kinh (NCAM) ở chuột con.

Sau tuổi dậy thì, tế bào Sertoli ngừng tăng sinh, nhưng lại bắt đầu quá trình biệt hóa. Do đó, T3 góp phần xác định số lượng tế bào Sertoli ở tuổi dậy thì, tương ứng với thể tích tinh hoàn và số lượng tinh trùng ở tuổi trưởng thành [14], [19]. Hơn nữa, T3 điều hòa làm giảm thụ thể estrogen, và tăng thụ thể androgen, và bằng cách ức chế hoạt động của men aromatase làm giảm chuyển đổi testosterone thành 17 $\beta$-estradiol [20].

Gần đây, các thụ thể hormone tuyến giáp cũng được tìm thấy trong tế bào Leydig [21]. Trong tế bào Leydig của chuột thí nghiệm, T3 có ảnh hưởng đến sự tổng hợp steroid dựa trên thời gian tiếp xúc: tiếp xúc ngắn, T3 làm tổng hợp thụ thể hormone luteinizing (LH) và steroid, trong khi tiếp xúc kéo dài, nó ức chế cả hai [22], [23]. T3 tác động trực tiếp và gián tiếp lên tế bào Leydig. Nó điều hòa tổng hợp yếu tố sinh steroid 1 và protein điều hòa tồng hợp steroid trong giai đoạn cấp tính (StAR). T3 tác động gián tiếp thông qua con đường kế cận liên quan đến các tế bào Sertoli [19, 24].

Hơn nữa, T3 điều hòa sự biệt hóa tế bào Leydig $[19,25]$. Tế bào Leydig cũng biểu hiện thụ thể estrogen, điều hòa tổng hợp testosterone và ức chế sự tăng sinh tế bào Leydig [26]. Nhìn chung, T3 điều chỉnh sự tăng sinh và biệt hóa tế bào Sertoli và tế bào Leydig.

\section{Anh hương trên tinh trùng}

Hormone tuyến giáp tác động trực tiếp lên tinh trùng theo cơ chế ngoài gen ở các mức độ khác nhau: màng tế bào chất (trên kênh canxi), tế bào chất, bộ xương tế bào và ti thể [27], [28]. Trong một nghiên cứu gần đây, Mendeluk và đồng nghiệp thấy rằng bổ sung $\mathrm{T} 4$ nhanh vào quá trình chuẩn bị tinh trùng (sau 20 phút) và thấy có cải thiện đáng kể khả năng vận động tinh trùng và cũng làm tăng số lượng tinh trùng hồi phục bằng kỹ thuật "bơi lên". Các tác giả đề ra giả thuyết rằng $\mathrm{T} 4$ tác động trực tiếp trên các kênh canxi, tăng hấp thu canxi và tăng tổng hợp cAMP, và gây hoạt hóa protein kinase, ngược lại gây ra các chuyển động hình sao dẫn đến cái gọi là "tăng động". Nhìn chung, T4 dường như cải thiện hoạt động tinh trùng nhiều hơn pentoxifylline, một chất ức chế phosphodiesterase $\mathrm{cAMP}$ thường được sử dụng trong môi trường nuôi cấy để tăng số lượng tinh trùng được phục hồi [28]. Dựa trên bằng chứng này, T4 dường như điều chỉnh tăng khả năng di chuyển của tinh trùng.

Anh hương trên các protein gắn hormon sinh sản

Trước khi phát hiện vai trò quan trọng của các receptor hormon tuyến giáp, người ta đã thừa nhận rằng $\mathrm{LH}, \mathrm{FSH}$ và testosteron điều hòa quá trình sản sinh tinh trùng. Testosteron có vai trò quan trong đảm bảo cho quá trình sinh tinh thành công. Nếu không có testosteron, quá trình phân chia từ tinh nguyên bào thành tiền tinh trùng sẽ bị rối loạn.

Hormon tuyến giáp cũng ảnh hưởng tới globulin gắn hormon sinh sản $(\mathrm{SHBG})$ và protein gắn androgen $(\mathrm{ABP})$. SHBG và $\mathrm{ABP}$ có cùng một trình tự axit amin, vì chúng được mã hóa bởi cùng một gen SHBG nhưng có thay đổi sau quá trình phiên mã và được tổng hợp ở các vị trí khác nhau. SHBG được sản xuất ở gan và $\mathrm{ABP}$ tạo ra ở tế bào Sertoli. Người ta cho rằng $\mathrm{ABP}$ được bài tiết cả trong máu và ống dẫn tinh. Cả hai đều là chất mang vận chuyển testosteron và estradiol. ABP có liên quan đến việc duy trì môi trường androgen trong tinh hoàn cần cho sự biệt hóa 
và trưởng thành của tế bào mầm. T3 là chất kích thích tổng hợp SHBG và có thể được xem là một dấu ấn sinh học cho tác dụng của hormon tuyến giáp. Ở chuột suy giáp, nồng độ SHBG giảm trong khi ở chuột cường giáp, nồng độ $\mathrm{SHBG}$ lại tăng. Bổ sung $\mathrm{T} 3$ làm giảm sản xuất $\mathrm{ABP}$ ở các tế bào Sertoli [15], [16]. Người ta thấy tế bào của chuột cường giáp 28 ngày tuổi giảm sản xuất $\mathrm{ABP}$ [29]. Ngược lại, theo JN Rao và cộng sự, ở chuột suy giáp trước tuổi dậy thì có giảm đáng kể nồng độ mRNA ABP [30]. Tương tự, nồng độ TR alpha mRNA tăng đáng kể ở chuột suy giáp 21 ngày tuổi và bị ức chế ở chuột cường giáp, không thấy có thay đổi trong trường hợp bình giáp. Người ta cho rằng hormon tuyến giáp có chức năng điều hòa sự trưởng thành của tế bào Sertoli sau sinh ở chuột trước giai đoạn dậy thì. Vì vậy, hormon tuyến giáp kiểm soát sự biểu hiện $\mathrm{ABP}$ ở các tế bào Sertoli nhưng bằng cách nào thì người ta còn chưa rõ [31]. Một trong các tác dụng của hormon tuyến giáp trên quá trình sinh tinh có thể là thông qua điều hòa tổng hợp SHBG.

Tác dụng trên hệ thống oxi hóa khư của tinh hoàn

Hormone tuyến giáp cũng điều hòa hệ thống oxi hóa khử tinh hoàn. Quá trình sản sinh tinh trùng và tổng hợp steroid là hai quá trình tiêu thụ nhiều năng lượng. Hơn thế nữa, tinh hoàn rất giàu axit béo không bão hòa, các axit này có thể bị peroxide hóa bởi các chất tiền oxi hóa. Ngược lại, các gốc oxi hóa tự do gây rối loạn quá trình tổng hợp steroid. Để cân bằngquá trình tạo các gốc oxi hóa tự do, tinh hoàn được trang bịmột loạt hệ thống chống oxy hóa phức tạp, bao gồm các enzym (chẳng hạn như superoxide dismutase, glutathione peroxidase, glutathione-Stransferase và gamma-glutamyltransferase), và các phân tử / phần tử không phải enzym (chẳng hạn như kẽm, cytochrome $\mathrm{C}$, melatonin và vitamin $C$ và $E$ ) [32]. Ví dụ, tăng biểu hiện quá mức của gamma-glutamyl transferase, một loại enzyme phổ biến đóng vai trò là yếu tố chính trong dị hóa glutathione, làm giảm nồng độ glutathione, và ức chế sự tổng hợp steroid dưới tác dụng của LH ở chuột [32].

Tinh hoàn và tuyến giáp đều giàu các protein chứa selenium. Giống deiodinase và thioredoxin reductase, glutathione peroxidase là một enzym chứa selenium có hoạt tính chống oxi hóa. Ở tinh hoàn, người ta đã tìm thấy glutathione peroxidase trong các tinh trùng (nhân, vùng trung gian và ti lạp thể), trong các tế bào Sertoli và trong các tế bào biểu mô mào tinh. Đặc biệt, ở tinh trùng trưởng thành, glutathione peroxidase chiếm khoảng $50 \%$ protein vỏ ti lạp thể ở vùng trung gian. Khi nồng độ glutathione giảm nhiều, glutathione peroxidase tập trung trong nguyên sinh chất nơi nó có chức năng chống oxi hóa. Ngược lại, khi nồng độ glutathione giảm it, glutathione peroxidase bị bất hoạtvà nó tập trung trong màng ty lạp thể nơi nó biểu hiện chức năng chống chết theo chương trình [33], [34], [35].

Chuột đực thiếu selen có biểu hiện chậm phát triển tinh hoàn trong thời kỳ dậy thì, giảm bài tiết testosterone ở tinh hoàn, và teo các ống dẫn tinh [34]. Trong một nghiên cứu đối chứng với giả dược được thực hiện trên nam giới của các cặp đôi đang tìm kiếm hỗ trợ sinh sản ở một khu vực ít selen (Tây Scotland), bổ sung selen cải thiện khả năng vận động của tinh trùng, nhưng không cải thiện mật độ tinh trùng, và cho phép đạt được mong muốn có con ở khoảng một trong số mười bệnh nhân được điều trị, ngược lại không có ai trong nhóm chứng có con. Hơn nữa, tinh hoàn chứa mộtsố selenoprotein khác, chẳng hạn như selenoprotein V. Giảm selenoprotein tinh hoàn có liên quan đến vô sinh. Tóm lại, mất cân bằng trạng thái oxi hóa khử của tinh hoàn làm thay đổi chức năng tinh hoàn ở các mức độ khác nhau, dẫn tới vô sinh.

\section{3. ẢNH HƯỞNG CỦA CƯờNG GIÁP VÀ SUY GIÁP}

Cả cường giáp và suy giáp gây ra các thay đổi về tinh hoàn, hormon và tinh dịch.

\subsection{Cường giáp}

Ở chuột, cường giáp có liên quan với việc tế bào leydig chậm trưởng thành, thay đổi quá 
trình sinh tinh trùng, tăng lipid peroxidation và nồng độ catalase, giảm nồng độ glutathione peroxidase [36],[37].

Ở nam giới trưởng thành, Hudson và Edward thấy rằng bệnh nhân cường giáp có nồng độ gonadotropins, SHBG, testosterone, $17 \beta$-estradiol và, đôi khi nồng độ prolactin cao hơn so với nhóm chứng bình giáp (do tăng $17 \beta$-estradiol) và nồng độ các chất này trở về bình thường khi đạt được tình trạng bình giáp.

Ngược lại, tăng SHBG huyết tương làm giảm testosterone tự do có hoạt tính sinh học. Nồng độ $\mathrm{T} 4$ tương quan thuận với nồng độ $\mathrm{LH}$, nhưng tương quan nghịch với nồng độ testosterone. Hơn nữa, sau kích thích GnRH, đáp ứng $\mathrm{LH}$ cũng tăng, trong khi đáp ứng testosterone, 17ß-estradiol hoặc prolactin đều giảm sau kích thích hCG hoặc TRH tương ứng.

Ở chuột nam cường giáp có sự giảm chức năng tinh trùng xác định bởi tính toàn vẹn của không bào, tính toàn vẹn của màng bào tương và hoạt động ti lạp thể. Một số nghiên cứu cho thấy giảm vận động tinh trùng (tinh trùng yếu) gặp trong khoảng $60 \%$ bệnh nhân cường giáp trưởng thành, nó trở về bình thường sau điều trị với các thuốc kháng giáp trạng. Các bất thường tinh dịch đồ khác gặp ở bệnh nhân cường giáp là giảm tinh trùng $(61 \%)$, số lượng tinh trùng thấp (oligozoospermia, $42 \%$ ), và tăng số lượng tinh trùng với hình thái thay đổi (teratozoospermia, 40\%). Tuy nhiên, các thông số sinh hóa tinh dịch đồ nhưnồng độ fructose, kẽm và magiê, vẫnkhông thay đổi [38], [39], [40] (Bảng 2).

Bảng 2. Tóm tắt các thay đổi của tinh dịch đồ khi cường giáp hoặc suy giáp

\begin{tabular}{|c|c|c|c|c|}
\hline $\begin{array}{c}\text { Tuyến } \\
\text { giáp }\end{array}$ & $\begin{array}{c}\text { Thể tích } \\
\text { tinh dịch }\end{array}$ & $\begin{array}{c}\text { Mật độ } \\
\text { tinh trùng }\end{array}$ & $\begin{array}{c}\text { Khả năng di } \\
\text { động tinh trùng }\end{array}$ & $\begin{array}{c}\text { Hình thái } \\
\text { tinh trùng }\end{array}$ \\
\hline Cường giáp & $\begin{array}{c}\text { Mật độ tinh trùng } \\
\text { yếu }\end{array}$ & $\begin{array}{c}\text { Mật độ tinh trùng } \\
\text { thấp }\end{array}$ & di động kém & bất thường \\
\hline Bình giáp & $\begin{array}{c}\text { Thể tích bình } \\
\text { thường }\end{array}$ & $\begin{array}{c}\text { Mật độ bình } \\
\text { thường }\end{array}$ & Bình thường & Bình thường \\
\hline Suy giáp & & & & Bất thường \\
\hline
\end{tabular}

So với các đối tượng bình giáp, bệnh nhân nhiễm độc giáp hay phàn nàn về xuất tinh sớm,rối loạn cương dương, giảm ham muốn tình dục và vú to nam giới [18], [41]. Trong một nghiên cứu cắt ngang gần đây trên 163nam giới vô sinh, tỷ lệ cường giáp dưới lâm sàng hoặcsuy giáp dưới lâm sàng là 4 hoặc 7\%. Các tác giả cũngtìm thấy mối tương quan thuận giữa $\mathrm{T} 3$ tự do với thể tích xuất tinh, thể tích túi tinh (trước và sau khi xuất tinh),sự làm rỗng túi tinh và nồng độ fructose trong túi tinh. So với những bệnh nhân suy giáp dưới lâm sàng, ở bệnh nhân cường giáp dưới lâm sàng, sự khác biệt giữa thể tích túi tinh trước và sauxuất tinh cao hơn đáng kể. Điều này cho thấy vai trò quan trọng củahormone tuyến giáp trên chức năng của tuyến phụ của nam giới. Ngoài ra, các thông số về tinh dịch và hormone không tương quanvới chức năng tuyến giáp. Tuy nhiên, hạn chế lớn của nghiên cứu này là số lượng đối tượng nghiên cứu ít, không cho phép đưa ra kết luận chắc chắn về ảnh hưởng của rối loạn chức năng tuyến giáp trên khả năng sinh sản của nam giới [42]

Tóm lại, cường giáp ảnh hưởng đến khả năng sinh sản nam giới ở mức độ hormone và tinh dịch đồ.

\subsection{Suy giáp}

Trong mô hình chuột được gây suy giáp, người ta thấy có sự giảm đáng kể nồng độ testosterone trong huyết thanh, mất hoạt động tình dục và xuất tinh, và giảm khối lượng mào tinh và tiền liệt tuyến. Hơn nữa, suy giáp thai kỳ gây ra ở con đực: (i) thay đồi khả năng di chuyển của tinh trùng, (ii) giảm hoạt tính sinh học androgen (iii) giảm biểu hiện và chức năng của thụ thể androgen và (iv) giảm hoạt động bài tiết mào tinh hoàn [43], [44]. Suy giáp cũng làm thay đổi trạng thái oxy hóa khử ở chuột trưởng thành, như tăng đáng kể các chỉ điểm stress oxy hóa (như hàm lượng 
protein carbonyl) và các chỉ điểm peroxide hóa lipid (ước tính bằng cách theo dõi sự tạo thành chất phản ứng với axit thiobarbituric), trong khi giảm nồng độ superoxide dismutase và catalase. Khi điều trị bằng $\mathrm{T} 3$, nồng độ catalase tăng,trong khi các chỉ điểm stress oxy hóa vẫn ở mức cao trong phân đoạn sau ti lạp thể của tinh hoàn [14], [15]. Ngoài ra,suy giáp cũng liên quan đến giảm glutathioneperoxidase ở chuột trưởng thành.

Ở nam giới trưởng thành, suy giáp gây ra những thay đổi hormone một phần theo hướng ngược lại so với nhiễm độc giáp: giảm nồng độ $\mathrm{SHBG}$, testosterone toàn phần, 17ßestradiol và hormone hướng sinh dục trong huyết thanh, trong khi làm tăng nồng độ prolactin. Sự thay đổi này có thể hồi phục khi điều trị thay thế hormone tuyến giáp.

Ở chuột đực suy giáp, sản xuất tinh trung giảm trong khi thời gian vận chuyển tinh trùng qua mào tinh tăng. Hơn nữa, tương tự như nhiễm độc giáp, suy giáp cũng làm giảm chức năng tinh trùng chuột. Ở người người ta thấy có sự giảm có hồi phục tinh trùng với hình thái bình thường (bảng 1 ). Ở bệnh nhân suy giáp, dị dạng tinh trùng có tương quan nghịch với nồng độ T4 [18]. Hơn nữa, bất kể thời gian suy giápbao lâu, chức năng tuyến phụ cũng bị ảnh hưởng vì làm giảm nồng độ glucose, sialic acid, và fructose tinh dịch. Vì đủ T3 là cần thiết để ức chế sự tăng sinh tế bào Sertoli và Leydig và gây biệt hóa của chúng, ở bệnh nhân suy giáp trước tuổi dậy thì thể tích tinh hoàn tăng, trong khi tinh trùng trưởng thành trong ống dẫn tinh giảm.

Giống như nhiễm độc giáp, suy giáp ảnh hưởng đến chức năng cương dương và xuất tinh, vì bệnh nhân suy giáp có thể phàn nàn về rối loạn cương dương và đôi khi phàn nàn về xuất tinh chậm và giảm ham muốn tình dục [14], [18].

Dựa trên bằng chứng này và tương tự như nhiễm độc giáp, người ta thấy suy giáp ảnh hưởng đến khả năng sinh sản của nam giới ở các các cấp độ khác nhau.

Bất kể chức năng tuyến giáp, ở bệnh nhân trưởng thành có viêm tuyến giáp tự miễn mãn tính, tỷ lệ kháng thể peroxidase tuyến giáp
(TPOAb) dương tính ở nhóm bệnh nhân có tinh trùng yếu hoặc dị dạng cao hơn. Người ta vẫn chưa biết liệu TPOAb có tác động trực tiếp hay gián tiếp trên tinh trùng hay không.

4. SỰ TƯƠNG TÁC GIŨA HORMONE TUYẾN GIÁP VỚI CÁC HORMONE KHÁC VÀ YẾU TỐ TĂNG TRỬ̛̉ TRONG ĐIỀU HÒA CHỨC NĂNG HỆ SINH SẢN NAM.

\subsection{Prolactin}

Người ta thấy dùng liều sinh lý prolactin trên tế bào Sertoli có ảnh hưởng trực tiếp làm tăng tổng hợp $\mathrm{ABP}$, đóng vai trò quan trọng trong tăng sinh và chuyển hóa tế bào Sertoli [81]. Một nghiên cứu của Koivisto và cộng sự trên Beagles đực thấy tăng đáng kể nồng độ prolactin khi tiêm tĩnh mạch 1 mũi thyroxin trong tăng prolactin máu ngắn hạn do metoclopramide. Lưu ý, không có thay đổi về chất lượng tinh dịch, $\mathrm{LH}$, và nồng độ testosterone. Tuy nhiên, mức prolactin cao hơn rõ rệt ở bệnh nhân suy giáp so với nhóm chứng $(\mathrm{P}<0,001)[45]$.

\subsection{Growth hormone}

Tăng nồng độ hormone tăng trưởng và chứng to đầu chi có thể liên quan đến rối loạn chức năng tuyến giáp. Tỷ lệ rối loạn chức năng cương dương ở 57 bệnh nhân to đầu chi là $42,1 \%$, đặc biệt trong trường hợp mắc bệnh kéo dài [46].

\subsection{Insulin-like growth factor (IGF)-1}

Bằng cách tăng hoạt tính sinh học của IGF3 thông qua việc chặn các protein gắn IGF, người ta thấy T3 và IGF-3 kích thích sự tăng sinh và biệt hóa chủ yếu của loại tinh nguyên bào không biệt hóa type $\mathrm{A}$ [47].

\subsection{Leptin}

Suy giáp có thể gây tăng cân và béo phì [46]. Leptin được sản xuất bởi các tế bào mõ và được cho là có các tác động trung tâm và ngoại vi lên các mô sinh sản. Người ta thấy biểu hiện của các receptor leptin trong các tế bào Leydig, tuyến tiền liệt và các túi tinh, ảnh hưởng đến chức năng sinh sản của nam giới [47]. Người ta thấy Leptin ức chế testosterone trong tinh hoàn [39]; Tuy nhiên, nó có một tác động gián tiếp là điều hòa chức năng $\mathrm{GnRH}$ [32]. Tăng leptin máu gây bộc lộ tín hiệu 
cytokine-3, ức chế bộ chuyển đổi tín hiệu phosphoryl hóa, và kích hoạt biểu hiện phiên mã-3. Điều này dẫn đến giảm trọng lượng và khối lượng của tinh hoàn cũng như đường kính của các ống dẫn tinh và số lượng tế bào sinh tinh [33], [34]. Đồng thời cũng có sự tương tác giữa hormone tuyến giáp và leptin; người ta thấy có mối tương quan thuận giữa TSH và leptin và chỉ số khối cơ thể. Ở bệnh nhân suy giáp, nồng độ leptin huyết thanh có thể tăng lên để khắc phục tình trạng tăng trọng lượng cơ thể do suy giáp [36].

\section{KẾT LUẬN}

Mối tương tác giữa chức năng tuyến giáp và chức năng tinh hoàn đã được chứng minh trong các nghiên cứu in vitro và in vivo, cả ở động vật và ở người. Tuy nhiên, cơ chế tương tác xảy ra hoàn toàn không rõ. Cả cường giáp và suy giáp đều có tác động lớn trên khả năng sinh sản, có thể gây ảnh hưởng thoáng qua hoặc vĩnh viễn. Xác định và điều trị vô sinh có liên quan với cường giáp hoặc suy giáp cần có sự kết hợp giữa các nhà nam học, nội tiết, sản khoa và các bác sĩ đa khoa. Cần có các nghiên cứu lớn hơn trên đối tượng bệnh nhân phù hợp để hiểu thêm về cơ chế rối loạn khả năng sinh sản ở người có rối loạn chức năng tuyến giáp.

\section{TÀI LIỆ THAM KHẢO}

1. Vanderpump M, Jefferys A, Yasmin E (2015). Thyroid dysfunction and reproductive health. Obstet Gynaecol, 17, $39-45$.

2. Thangaratinam S, Tan A, Knox E et al (2011). Association between thyroid autoantibodies and miscarriage and preterm birth: meta-analysis of evidence. Br Med J,342, d2616.

3. Van den Boogaard E, Vissenberg R, Land JA et al (2011). Significance of (sub)clinical thyroid dysfunctionand thyroid autoimmunity before conception and in early pregnancy: a systematic review. Hum Reprod Update, 17, 605-619.
4. Cignini $\mathrm{P}$, Cafa` EV, Giorlandino $\mathrm{C}$ et al (2012). Thyroid physiology and common diseases in pregnancy: review ofliterature. J Prenat Med, 6, 64-71.

5. Rajender S, Monica MG, Walter L, Agarwal A (2011). Thyroid, spermatogenesis, and male infertility. Front Biosci,3, 843-855.

6. Krassas GE, Poppe K, Glinoer D (2010). Thyroid function and human reproductivehealth. Endocr Rev, 31, 702 -755 .

7. Krajewska-Kulak E, Sengupta P (2013). Thyroid function in male infertility. Front Endocrinol (Lausanne), 4, 1 - 2.

8. Krassas GE, Perros P (2003). Thyroid disease and male reproductive function. $J$ Endocrinol Invest, 26, 372 - 380

9. Krassas GE, Pontikides N, Deligianni V, Miras K (2002). A prospective controlled study of the impact of hyperthyroidism on reproductive function in males. J Clin Endocrinol Metab,87, 3667-3671.

10. Krassas GE, Papadopoulou F, Tziomalos $\mathrm{K}$ et al (2008). Hypothyroidism has an adverse effect on human spermatogenesis: a prospective, controlled study. Thyroid, 18, 1255 1259.

11. Van Steirteghem A, Glinoer D Poppe K, Tournaye $\mathrm{H}$ et al (2002). Thyroid dysfunction and autoimmunity ininfertile women. Thyroid, 12, $997-1001$.

12. Wang C, Crapo LM (1997). The epidemiology of thyroid disease and implications forscreening. Endocrinol Metab Clin North Am, 26, 189 - 218.

13. Whitted WA, Strickland DM, Wians FH Jr (1990). Screening infertile women for subclinical hypothyroidism.Am $J$ Obstet Gynecol, 163, 262-263.

14. Sandro La Vignera, Roberto Vita et al (2017). Impact of thyroid disease on testicular function. Endocrine,

15. Singh Rajender1, Marie Gray Monica, Lee Walter, Ashok Agarwal (2011). Thyroid, spermatogenesis, and male 
infertility. Frontiers in Bioscience E3, 843-855.

16. Ahmed Alahmar1, Sulagna Dutta, Pallav Sengupta (2019). Thyroid hormones in male reproduction and infertility. Asian Pacific Journal of Reproduction, 8(5): 203-210

17. D.R. Holsberger, P.S. Cooke, Understanding the role of thyroidhormone in Sertoli cell development: a mechanistic hypothesis.Cell. Tissue Res. 322, 133140 (2005)

18. G.E. Krassas, K. Poppe, D. Glinoer, Thyroid function and humanreproductive health. Endocr. Rev. 31, 702-755 (2010)

19. R. Singh, A.J. Hamada, A. Agarwal(2011). Thyroid hormones inmale reproduction and fertility. Open Reprod. Sci. J 3, 98-104

20. S. Andò, R. Sirianni, P. Forastieri et al (2001). Aromataseexpression in prepuberal Sertoli cells: effect of thyroid hormone.Mol. Cell Endocrinol. 178, 1121

21. J.J. Buzzard, J.R. Morrison, M.K. O’Bryan, Q. Song, N.G. Wreford(2000). Developmental expression of thyroid hormone receptors inthe rat testis. Biol. Reprod. 62, 64-69

22. P.R. Manna, J. Kero, M. Tena-Sempere, et al (2001). Assessment of mechanisms of thyroidhormone action in mouse Leydig cells: regulation of the steroidogenicacute regulatory protein, steroidogenesis, and luteinizinghormone receptor function. Endocrinology 142, 319-331

23. P.R. Manna, M. Tena-Sempere, I.T. Huhtaniemi(1999).

Molecularmechanisms of thyroid hormone-stimulated steroidogenesis inmouse leydig tumor cells. Involvement of the steroidogenic acuteregulatory (StAR) protein. J. Biol. Chem. 274, 59095918

24. R.R. Maran, J. Arunakaran, M.M. Aruldhas (2000). T3 directly stimulatesbasal and modulates $\mathrm{LH}$ induced testosterone and oestradiolproduction by rat Leydig cells in vitro. Endocr. J. 47, 417-428

25. S.M. Mendis-Handagama, H.B. Ariyarante(2001). Differentiation of theadult Leydig cell population in the postnatal testis. Biol. Reprod.65, 660 671.

26. A.M. Nakhla, J.P. Mather, O.A. Jänne, C.W. Bardin (1984). Estrogen andandrogen receptors in Sertoli, Leydig, myoid, and epithelial cells:effects of time in culture and cell density. Endocrinology 115,121-128

27. P.J. Davis, F. Goglia, J.L. Leonard(2016). Nongenomic actions ofthyroid hormone. Nat. Rev. Endocrinol. 12, 111-121

28. G.R. Mendeluk, M. Rosales(2016). Thyroxin is useful to improve spermmotility. Int. J. Fertil. Steril. 10 , 208-214

29. S Palmero, M de Marchis, G Gallo, E Fugassa(1989). Thyroid hormone affects the development of Sertoli cell function in the rat. $J$ Endocrinol 123, 105-11

30. JN Rao, JY Liang, P Chakraborti, P Feng (2003). Effect of thyroid hormone on the development and gene expression of hormone receptors in rat testes in vivo. $J$ Endocrinol Invest 26, 435-443

31. E. Fugassa, S. Palmero, G. Gallo(1987). Triiodothyronine decreases the production of androgen binding protein by rat Sertoli cells. Biochem. Biophys. Res. Commun. 143, 241-247

32. W. Li, Z.Q. Wu, S. Zhang, R. Cao, J. Zhao, Z.J. Sun, W. Zou (2016). Augmented expression of gammaglutamyl transferase 5 (GGT5)impairs testicular steroidogenesis by deregulating local oxidative stress. Cell. Tissue. Res. $366,467-481$

33. D.H. Holben, A.M. Smith(1999). The diverse role of selenium within selenoproteins: a review. J. Am. Assoc. 99, 836-843 
34. L.H. Duntas, S. Benvenga(2015). Selenium: an element for life. Endocrine 48, 758-775

35. E.J. van Zuuren, A.Y. Albusta, Z. Fedorowicz, B. Carter, H. Pijl(2014). Selenium supplementation for Hashimoto's thyroiditis: summary of a cochrane systematic review. Eur. Thyroid. J 3, 25-31

36. E. Rijntjes, A.T. Wientjes, H.J. Swarts, D.G. de Rooij, K.J. Teerds(2008). Dietary-induced hyperthyroidism marginally affects neonatal testicular development. J. Androl. 29, 643-653

37. S. Choudhury, G.B. Chainy, M.M. Mishro (2003). Experimentally induced hypo- and hyper-thyroidism influence on the antioxidant defence system in adult rat testis. Andrologia 35, 131-140

38. R.W. Hudson, A.L. Edwards(1992). Testicular function in hyperthyroidism. $J$. Androl. 13, 117-124

39. G.E. Krassas(2005). The male and female reproductive system in thyrotoxicosis. Thyroid 9, 621-628

40. M. Abalovich, O. Levalle, R. Hermes, H. Scaglia et al (1999). Hypothalamicpituitary- testicular axis and seminal parameters in hyperthyroid males. Thyroid 9, 857-863

41. G.E. Krassas, N. Pontikides, V. Deligianni, K. Miras(2002). A prospective controlled study of the impact of hyperthyroidism on reproductive function in males. J. Clin. Endocrinol. Metab. 87, 3667-3671

42. F. Lotti, E. Maseroli, N. Fralassi (2016). Is thyroid hormones evaluation of clinical value in the work-up of males of infertile couples? Hum. Reprod. 31, 518-529

43. J. Anbalagan, A.M. Sashi, G. Vengatesh, J.A. Stanley (2010). Mechanism underlying transient gestational-onset hypothyroidism-induced impairment of posttesticular sperm maturation in adult rats. Fertil. Steril. 93, 2491-2497

44. M.M. Aruldhas, N. Ramalingam, A. Jaganathan et al (2010). Gestational and neonatal-onset hypothyroidism alters androgen receptor status in rat prostate glands at adulthood. Prostate 70, 689700

45. Nikoobakht MR, Aloosh M, Nikoobakht N et al (2012). The role of hypothyroidism in male infertility and erectiledysfunction. Urol J; 9(1): 405-409.

46. Lotti F, Rochira V, Pivonello R, Santi D, Galdiero M, Maseroli E, et al (2015). Erectile dysfunction is common among men with acromegaly and isassociated with morbidities related to the disease. $J$ Sex Med; 12(5): 1184-1193.

47. Safian D, Morais RDVS, Bogerd J, Schulz RW (2016). Igf binding proteins protect undifferentiated spermatogonia in the zebrafish testis againstexcessive differentiation. Endocrinology; 157(11): 4423-4433. 